\title{
Hepatitis C treatment outcomes in Australian clinics
}

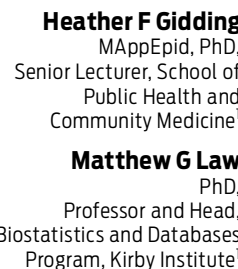

Janaki Amin

Senior Lecture Kirby Institute

George Ostapowicz BMed, MD, FRACP. Director of
Direto

Gastroenterology

Martin Weltman PhD, FAChAM, FRACP, Associate Professo and Director ${ }^{3}$

Graeme A Macdonald MB BS, PhD, FRACP Gastroenterologist

Joe J Sasadeusz MB BS, PhD, FRACP, Infectious Diseases Physician

Paul AW Habe MD, FRACP, FAChAM Senior Staff Specialist and Head of Drug Health Services $^{6}$

Jacob George MB BS, PhD, FRACP Professor and Director

Gregory J Dore MPH, PhD, FRACP, Professor and Head, Viral Hepatitis Clinical Research Program, Kirby Institute

1 University of New South Wales, Sydney, NSW.

2 Gold Coast Hospital,

Southport, QLD.

3 Nepean Hospital, Sydney, NSW.

4 Princess Alexandra Hospital, Brisbane, QLD.

5 Infectious Diseases Service, Royal Melbourne Hospital, Melbourne, VIC

6 Gastroenterology and Liver Centre, Royal Prince Alfred Hospital, Sydney, NSW.

$\mathbf{7}$ Storr Liver Unit, Millennium Institute for

Medical Research, Sydney, NSW.

hgidding@unsw.edu.au

MJA 2012; 196: 633-637 doi: 10.5694/mjal2.10014 linical trials have proven the efficacy of pegylated interferon- $\alpha$ plus ribavirin for the treatment of chronic hepatitis $\mathrm{C}$ virus (HCV) infection. ${ }^{1-4}$ They also report that a variety of patient and virological factors influence treatment response, in particular, HCV genotype and extent of hepatic fibrosis. However, trials typically employ strict patient selection criteria and exclude patients with a range of comorbid conditions (such as HIV or hepatitis B coinfection, and drug- and alcohol-related problems), which are frequent among the HCV-infected population. In addition, patients volunteering for trials are probably more likely to adhere to treatment because of greater motivation and more intense monitoring than would occur in the "real-world" clinic setting. ${ }^{5}$

A few multiclinic observational studies have been conducted to measure the real-world "effectiveness" of HCV treatment. ${ }^{6-9}$ However, these studies also incorporated strict selection criteria and did not examine the influence of lifestyle-related factors on treatment response. Furthermore, there has only been one clinic-based study in Australia, conducted in a single tertiary hospital clinic and before the availability of pegylated interferon. ${ }^{5}$ The aim of our study was to determine treatment response rates and predictors of response within a previously HCV-treatment-naive population using data collected prospectively from a large network of HCV clinics across Australia that employ usual care practices.

\section{Methods}

\section{Patient selection}

The Australian Chronic Hepatitis C Observational Study (ACHOS) recruitment and data collection

\section{Abstract}

Objective: To determine hepatitis C (HCV) treatment effectiveness and predictors of response in the "real-world" Australian clinic setting.

Design, setting and participants: Patients with chronic HCV, who were HCVtreatment-naive at enrolment, and were then treated with standard therapy (pegylated interferon- $\alpha$ plus ribavirin), were recruited prospectively through a national network of $24 \mathrm{HCV}$ clinics between April 2008 and December 2009. Patients were interviewed and a medical record review was conducted at enrolment and at routine follow-up clinic visits.

Main outcome measures: Proportion of patients achieving a sustained virological response (SVR), predictors of SVR, and impact of treatment on biochemical markers of liver disease (alanine aminotransferase levels and aspartate aminotransferase-to-platelet ratio index scores).

Results: The SVR by intention to treat was 60\% (327/550). Infection with HCV genotype 2 or 3 (compared with genotype 1) was an independent predictor of SVR (odds ratio [OR], 2.45; 95\% Cl, 1.70-3.52), while HIV coinfection (OR, 0.28; $95 \% \mathrm{Cl}, 0.10-0.82$ ), cirrhosis (OR, 0.38; $95 \% \mathrm{Cl}, 0.18-0.81$ ), and increased body mass index for $\geqslant 30 \mathrm{~kg} / \mathrm{m}^{2} \mathrm{v} \leqslant 25 \mathrm{~kg} / \mathrm{m}^{2}$ (OR, 0.58; 95\% Cl, 0.35-0.96) were independently associated with lower SVR. There was a significant improvement in biochemical markers of liver disease following SVR $(P<0.001)$.

Conclusions: Our findings are similar to those seen in clinical trials, despite the inclusion of patients with a broad range of comorbid conditions such as injecting drug and alcohol use and psychiatric illness. They suggest that, with appropriate patient and infrastructure support, expansion of treatment services to the broader HCV-infected community is warranted.

methods have been detailed previously. ${ }^{10}$ In brief, to provide broad geographical and clinic type distribution, the ACHOS included 24 clinics across four Australian states and the Australian Capital Territory, involving a variety of settings such as major metropolitan hospitals, regional, drug dependency and primary care clinics, and correctional centres. Patients were recruited prospectively between April 2008 and December 2009, based on eligibility for subsidised HCV treatment under the Section 100 - Highly Specialised Drugs Program. ${ }^{11}$ The Section 100 treatment eligibility criteria are broad; treatment is available for all patients aged $\geqslant 18$ years, provided they are using effective forms of contraception and have compensated liver disease. ${ }^{11}$ At the time of enrolment into ACHOS, patients were interviewed by the study coordinator and/or investigator at each clinic and their medical and pathology records were also reviewed to obtain demographic, lifestyle and clinical information. Follow-up visits were according to routine clinical care requirements, when data about changes in treatment or reason for treatment deferral, any liver-related complications, and new pathology test results were recorded.

To examine treatment outcomes, the ACHOS cohort was restricted to patients who were HCV-treatmentnaive at enrolment and were then treated with standard therapy (pegylated interferon- $\alpha$ plus ribavirin at doses determined by the treating clinician). To provide an unbiased selection of patients commencing treatment, we only included patients with an actual treatment stop date (if they completed the course) or a planned treatment stop date (if they did not complete the course) at least 28 
1 Selected baseline characteristics of patients in the Australian Chronic Hepatitis C Observational Study treated for the first time with pegylated interferon- $\alpha$ plus ribavirin $(n=550)$

\begin{tabular}{|c|c|c|}
\hline Characteristic & & No. \\
\hline Men & 344 & $(62.5 \%)$ \\
\hline Median age at treatment, years & 46 & (IQR, 39-52) \\
\hline Median body mass index, $\mathrm{kg} / \mathrm{m}^{2}$ & 25 & (IQR, 23-29) \\
\hline Australian born & 419 & $(76.2 \%)$ \\
\hline \multicolumn{3}{|l|}{ Hepatitis C infection-related } \\
\hline Median duration, years & 19 & (IQR, 10-27) \\
\hline Cirrhosis & 35 & $(6.4 \%)$ \\
\hline \multicolumn{3}{|l|}{ HCV genotype } \\
\hline 1 & 273 & $(49.6 \%)$ \\
\hline 2 & 31 & $(5.6 \%)$ \\
\hline 3 & 232 & $(42.2 \%)$ \\
\hline Other $(4,6,12)$ & 13 & $(2.4 \%)$ \\
\hline Unknown & 1 & $(0.2 \%)$ \\
\hline \multicolumn{3}{|l|}{ Lifestyle-related comorbid condition } \\
\hline Past injecting drug use & 374 & $(68.0 \%)$ \\
\hline Current injecting drug use & 29 & $(5.3 \%)$ \\
\hline Past drug dependency treatment & 72 & $(13.1 \%)$ \\
\hline Current drug dependency treatment & 91 & $(16.5 \%)$ \\
\hline Current alcohol consumption $\leqslant 20 \mathrm{~g} /$ day & 198 & $(36.0 \%)$ \\
\hline Current alcohol consumption $>20$ g/day & 35 & $(6.4 \%)$ \\
\hline Current daily tobacco use & 291 & $(52.9 \%)$ \\
\hline Current daily cannabis use & 49 & $(8.9 \%)$ \\
\hline Current < daily cannabis use & 96 & $(17.5 \%)$ \\
\hline History of treated depression & 123 & $(22.4 \%)$ \\
\hline History of other treated psychiatric illness & 65 & $(11.8 \%)$ \\
\hline HIV positive & 17 & $(3.1 \%)$ \\
\hline HBsAg positive & 13 & $(2.4 \%)$ \\
\hline
\end{tabular}

$\mathrm{IQR}=$ interquartile range.

weeks (24 weeks to obtain sustained virological response [SVR] plus 4 weeks to allow for delays in data entry) before the study database download date (12 August 2011).

\section{Main treatment outcome}

The main treatment outcome was whether or not a patient achieved an SVR, defined as undetectable HCV RNA at least 12 weeks (with preference to the result closest to 24 weeks) after treatment completion. The analysis was by intention to treat (ie, we included all patients who received at least one dose of therapy), and all missing SVR results were coded as failures.

\section{Statistical analysis}

To examine the impact of treatment on liver disease, we used the $\mathrm{McNemar}$ test to compare pretreatment and Week 24 after-treatment proportions of patients with normal alanine aminotransferase (ALT) levels $(\leqslant 19$ IU/L for women and $\leqslant 30 \mathrm{IU} / \mathrm{L}$ for men $^{12}$ ) and with an APRI score (aspartate aminotransferase-toplatelet ratio index) $\leqslant 0.5$ (consistent with no evidence of a significant fibrosis $\left.{ }^{13}\right)$.

To determine independent predictors of achieving an SVR, we performed multivariate logistic regression, including factors significantly associated $(P \leqslant 0.1)$ with an SVR in the univariate analysis. Modelling was performed using a stepwise backward elimination procedure, retaining only factors that were significant at $P \leqslant 0.05$ in the final model. A logistic regression model, conditional on clinic site, was also performed to ensure that results were robust to possible differences in patterns of treatment uptake between sites.

The University of New South Wales and the ethics committees representing each of the clinics granted ethics approval. All patients provided written informed consent.

\section{Results}

There were 1260 patients enrolled in ACHOS. Of these, 213 patients had received treatment previously, $446 \mathrm{did}$ not receive treatment, 32 were treated with regimens other than pegylated interferon- $\alpha$ plus ribavirin, and 19 had insufficient follow-up to determine their treatment outcome. This left a subcohort of 550 patients for analysis.

\section{Patient characteristics}

Patients in the study cohort had a range of lifestyle and clinical characteristics that would have led to many being excluded from clinical trials (Box 1).

\section{Treatment outcomes}

Sustained virological response. Evaluation of SVR was predominantly based on a record in the ACHOS database of an HCV RNA test result at least 20 weeks after treatment (394, $71.6 \%)$. Thirty-one patients (5.6\%) had a record only for testing at 12 weeks after treatment, and 78 patients (14.2\%) were coded as treatment failures due to missing SVR data. Fortyseven patients $(8.5 \%)$ did not have any recorded SVR virology results, but SVR was noted in their medical records and they were therefore coded as having an SVR.

The overall SVR by intention to treat was 59.5\% (327/550). Patients with genotype 1 infection had a lower SVR (135/273, 49.5\%) than those with genotype 2 or 3 infection $(183 / 263,69.6 \%)$.

\section{Reasons for treatment discontinua-}

tion. Seventy-five per cent $(414 / 550)$ of patients completed their treatment course; $10.0 \%$ (55/550) stopped because of non-response to treatment, $6.4 \%$ (35/550) because of an adverse event, and $4.7 \%$ (26/550) had "patient's decision" recorded as the reason for stopping. A range of adverse events were recorded, each with a frequency of 4 or less.

Biochemical responses to therapy. There was a significant improvement in biochemical markers of liver disease following treatment, especially in patients who achieved an SVR (Box 2).

Predictors of treatment response. Box 3 summarises the factors examined in the multivariate analysis (Supplementary Table 3 online at mja.com.au provides the full list). Notably, there was no association between SVR and injecting drug use status, alcohol consumption, tobacco or cannabis smoking, or history of psychiatric illness, although there was a trend towards lower SVR in patients with a non-depressive psychiatric illness or who were daily cannabis smokers. In the multivariate analysis, only lower body mass index (BMI), genotype 2 or 3 infection and not having HIV or cirrhosis remained independent predictors of SVR (Box 3). In a post-hoc analysis of the 221 (40\%) patients with a pretreatment cholesterol level recorded, a value $>5 \mathrm{mmol} / \mathrm{L}$ was associated with a higher SVR, when adjusted for other significant predictors (Box 3 ).

The conditional logistic regression model stratified by clinic showed similar results to the multivariate 
analysis described above (data not shown), indicating that there were no significant differences in the patterns of treatment response between clinics.

Restricting the analysis to the 273 patients with genotype 1 infection produced similar results to the model with all genotypes combined; independent predictors of SVR were lower BMI (odds ratio [OR], 2.40; $95 \% \mathrm{CI}, 1.19-4.84$; for $\leqslant 25 \mathrm{~kg} / \mathrm{m}^{2} \mathrm{v}$ $\geqslant 30 \mathrm{~kg} / \mathrm{m}^{2}$ ) and female sex (OR, 1.94; 95\% CI, 1.14-3.28). Having cirrhosis (OR, 0.12; 95\% CI, 0.03-0.56) or HIV coinfection (OR, 0.11; 95\% CI, 0.011.00) was associated with lower SVR. In contrast, for the 263 patients infected with genotype 2 or 3, only being $\mathrm{HBcAb}$ positive (OR, 0.48 ; $95 \%$ CI, 0.24-0.94) and current daily tobacco smoking (OR, 0.40; 95\% CI, 0.20-0.80; for current $\mathrm{v}$ past daily smokers) were independently associated with lower SVR. SVR for genotype 2 or 3 infection showed no trend by BMI, but there was a trend towards lower SVR in patients with cirrhosis (OR, 0.68; 95\% CI, 0.241.95 ) or HIV coinfection (OR, 0.49; 95\% CI, 0.13-1.93).

\section{Discussion}

In our Australian cohort of patients treated for the first time with pegylated interferon- $\alpha$ plus ribavirin, $60 \%$ achieved an SVR. Patients with genotype 1 infection had a lower SVR (50\%) than patients infected with genotype 2 or 3 (70\%). Other independent predictors of non-SVR included HIV coinfection, cirrhosis and increased BMI, but there was some variation in the importance of these predictors by genotype. For patients who achieved an SVR, we were able to show a significant improvement in biochemical markers of liver disease at 24 weeks after treatment. Although our findings were consistent with clinical trial data $^{1-4}$ and observational multiclinic studies in other countries, ${ }^{6-9}$ they are even more encouraging. This is because, unlike other studies to date, we included patients with a range of medical and lifestyle-related comor-

\begin{tabular}{|c|c|c|c|c|}
\hline & \multirow[b]{2}{*}{$\begin{array}{c}\text { No. of } \\
\text { patients }\end{array}$} & \multicolumn{2}{|c|}{ Proportion normal* } & \multirow[b]{2}{*}{$\begin{array}{c}P \text { (before } v \text { after } \\
\text { treatment) }\end{array}$} \\
\hline & & $\begin{array}{c}\text { Before } \\
\text { treatment (\%) }\end{array}$ & $\begin{array}{l}24 \text { weeks after } \\
\text { treatment }(\%)^{\dagger}\end{array}$ & \\
\hline \multicolumn{5}{|l|}{ ALT } \\
\hline No SVR & 122 & $3.3 \%$ & $6.6 \%$ & 0.375 \\
\hline SVR & 287 & $5.9 \%$ & $78.0 \%$ & $<0.001$ \\
\hline Total & 409 & $5.1 \%$ & $56.7 \%$ & $<0.001$ \\
\hline \multicolumn{5}{|l|}{$\mathrm{APRI}^{\ddagger}$} \\
\hline No SVR & 107 & $34.6 \%$ & $35.5 \%$ & 0.886 \\
\hline SVR & 235 & $42.6 \%$ & $88.9 \%$ & $<0.001$ \\
\hline Total & 342 & $40.1 \%$ & $72.2 \%$ & $<0.001$ \\
\hline
\end{tabular}

$\mathrm{ALT}=$ alanine aminotransferase. $\mathrm{APRI}=\mathrm{AST}$-to-platelet ratio index. $\mathrm{AST}=$ aspartate aminotransferase. *ALT $\leqslant 19 \mathrm{IU} / \mathrm{L}$ for women, $\leqslant 30 \mathrm{IU} / \mathrm{L}$ for $\mathrm{men} ;{ }^{12} \mathrm{APRI} \leqslant 0.5 . \dagger>10$ weeks and result closest to Week 24 after treatment ceased. $¥$ APRI score $=([$ AST/ULN]/platelet count $) \times 100$, where AST is in U/L, platelet count is $\times 10^{9}$, and ULN $=40 \mathrm{U} / \mathrm{L}^{13}$

bid conditions, based on Australia's broad eligibility criteria for treatment. ${ }^{11}$ By including such patients we were able to show that drug- and alcohol-related factors and psychiatric illness were not significant impediments to successful treatment outcomes.

In pivotal clinical trials of pegylated interferon $-\alpha$ plus ribavirin, SVRs were $54 \%-56 \%$ overall, $46 \%-52 \%$ for genotype 1 , and $76 \%-$ $84 \%$ for genotype 2 or 3 infection. ${ }^{1-4}$ Although our response rates for genotype 2 and 3 are slightly lower than these figures, all are within the range of those reported in realworld multiclinic studies conducted in North America and Europe, ${ }^{6-9}$ and a previous Australian study in one large tertiary clinic. ${ }^{5}$ Response rates in these studies were more varied $(48 \%-68 \%$ overall, $34 \%-56 \%$ for genotype 1, and $65 \%-89 \%$ for genotype 2 or 3 infection), reflecting differences in patient mix and treatment practices, which highlights the importance of real-world, countryspecific, estimates.

Our study confirms that a range of patient and viral factors are important predictors of treatment response. Cirrhosis and genotype 1 infection have consistently been reported as strong predictors of non-response. In our cohort, both these factors were significant, along with HIV coinfection and BMI. HIV coinfection is infrequently reported as a predictor of non-response in multiclinic studies, either because these patients are specifically excluded or because the number of patients with coinfection is too small to detect an association. Despite the low prevalence in our study, HIV coinfection remained a significant independent predictor of non-response, consistent with findings from clinical trials specifically examining HIV-coinfected cases, which report SVR rates that are $10 \%-20 \%$ lower than for HCVmonoinfected patients. ${ }^{14-15}$ A significant inverse correlation between BMI and SVR has been reported in other clinic-based studies. We found this association applied only to genotype 1 infection. Few clinic-based studies have examined genotypespecific models and findings have been mixed. ${ }^{7-9}$

Although not a prespecified covariate, there was a strong association between cholesterol levels and treatment response in the $40 \%$ of patients with pretreatment data. Other studies have reported that high cholesterol levels are associated with higher SVR. ${ }^{16-17}$ However, the underlying reasons for this association are unclear. $^{17}$

A unique aspect of our study was that we prospectively measured pretreatment injecting drug- and alcohol-related factors, including psychiatric illness, as well as cannabis and tobacco smoking status, and examined their independent impact on treatment response. 
3 Selected univariate and multivariate predictors of a sustained virological response (SVR) to hepatitis C treatment with pegylated interferon- $\alpha$ plus ribavirin* $(n=550)$

\begin{tabular}{|c|c|c|c|c|c|c|c|c|}
\hline \multirow[b]{2}{*}{ Predictor } & \multicolumn{2}{|r|}{ SVR } & \multicolumn{3}{|c|}{ Univariate analysis } & \multicolumn{3}{|c|}{ Multivariate analysis $^{\dagger}$} \\
\hline & No & Yes & OR $(95 \% \mathrm{Cl})$ & $P$ & P overall & OR $(95 \% \mathrm{Cl})$ & $P$ & P overall \\
\hline \multicolumn{9}{|l|}{ Sex } \\
\hline Men & 152 & $192(55.8 \%)$ & 1 & & & 1 & & \\
\hline Women & 71 & $135(65.5 \%)$ & $1.50(1.05-2.15)$ & 0.025 & & $1.43(0.98-2.08)$ & 0.065 & \\
\hline \multicolumn{9}{|c|}{ Age group at treatment start } \\
\hline$<35$ years & 30 & $60(66.7 \%)$ & 1 & & & 1 & & \\
\hline $35-44$ years & 60 & $98(62.0 \%)$ & $0.82(0.47-1.41)$ & 0.465 & $0.016^{\ddagger}$ & $0.93(0.53-1.64)$ & 0.527 & $0.198^{\ddagger}$ \\
\hline $45-54$ years & 99 & $139(58.4 \%)$ & $0.70(0.42-1.16)$ & 0.173 & & $0.89(0.52-1.52)$ & 0.517 & \\
\hline$\geqslant 55$ years & 34 & $30(46.9 \%)$ & $0.44(0.23-0.85)$ & 0.015 & & $0.59(0.30-1.19)$ & 0.297 & \\
\hline \multicolumn{9}{|l|}{ Body mass index } \\
\hline$\leqslant 25 \mathrm{~kg} / \mathrm{m}^{2}$ & 86 & $164(65.6 \%)$ & 1 & & & 1 & & \\
\hline $25-<30 \mathrm{~kg} / \mathrm{m}^{2}$ & 75 & $98(56.6 \%)$ & $0.69(0.46-1.02)$ & 0.063 & $0.008^{\ddagger}$ & $0.71 \quad(0.47-1.08)$ & 0.110 & $0.028^{\ddagger}$ \\
\hline$\geqslant 30 \mathrm{~kg} / \mathrm{m}^{2}$ & 46 & $48(51.1 \%)$ & $0.55(0.34-0.89)$ & 0.014 & & $0.58(0.35-0.96)$ & 0.033 & \\
\hline Unknown & 16 & 17 (51.5\%) & & & & & & \\
\hline \multicolumn{9}{|l|}{ HIV positive } \\
\hline No & 103 & $169(62.1 \%)$ & 1 & & & 1 & & \\
\hline Yes & 11 & $6(35.3 \%)$ & $0.33(0.12-0.93)$ & 0.035 & & $0.28(0.10-0.82)$ & 0.020 & \\
\hline Unknown & 109 & $152(58.2 \%)$ & & & & & & \\
\hline \multicolumn{9}{|c|}{ Duration of infection } \\
\hline$<10$ years & 42 & $84(66.7 \%)$ & 1 & & & 1 & & \\
\hline 10-19 years & 57 & $91(61.5 \%)$ & $0.80(0.49-1.31)$ & 0.374 & $0.016^{\ddagger}$ & $0.83(0.49-1.40)$ & 0.480 & $0.101^{\ddagger}$ \\
\hline$\geqslant 20$ years & 116 & $137(54.2 \%)$ & $0.59(0.38-0.92)$ & 0.020 & & $0.66(0.41-1.07)$ & 0.095 & \\
\hline Missing & 8 & $15(65.2 \%)$ & & & & & & \\
\hline \multicolumn{9}{|l|}{ Cirrhosis } \\
\hline No & 186 & $301(61.8 \%)$ & 1 & & & 1 & & \\
\hline Yes & 22 & $13(37.1 \%)$ & $0.37(0.18-0.74)$ & 0.005 & & $0.38(0.18-0.81)$ & 0.011 & \\
\hline Unknown & 15 & $13(46.4 \%)$ & & & & & & \\
\hline \multicolumn{9}{|l|}{ HCV genotype } \\
\hline 1 & 138 & $135(49.5 \%)$ & 1 & & & 1 & & \\
\hline 2 or 3 & 80 & $183(69.6 \%)$ & $2.36(1.65-3.35)$ & $<0.001$ & $<0.001^{5}$ & $2.45(1.70-3.52)$ & $<0.001$ & $<0.001^{5}$ \\
\hline Other & 4 & $9(69.2 \%)$ & $2.32(0.70-7.70)$ & 0.170 & & $2.25(0.66-7.65)$ & 0.196 & \\
\hline Unknown ${ }^{9}$ & 1 & 0 & & & & & & \\
\hline \multicolumn{9}{|l|}{ Cholesterol level** } \\
\hline$\leqslant 5 \mathrm{mmol} / \mathrm{L}$ & 73 & $98(57.3 \%)$ & 1 & & & 1 & & \\
\hline$>5 \mathrm{mmol} / \mathrm{L}$ & 9 & 41 (82.0\%) & $3.39(1.55-7.42)$ & 0.002 & & $4.07(1.78-9.29)$ & 0.001 & \\
\hline Unknown & 141 & 188 (57.1\%) & & & & & & \\
\hline
\end{tabular}

* Full results are provided in Supplementary Table 3 at mja.com.au. Note: Supplementary Table 3 is reproduced as supplied by the authors and has not been edited by the MJA. † Adjusted for other significant predictors of SVR included in the final model (body mass index, cirrhosis, HIV status, hepatitis C genotype; Hosmer-Lemeshow goodness-of-fit test for final model, $P=0.725$ ). $\ddagger P$ overall for linear trend. $\$ P$ overall for heterogeneity. 9 Results for these categories were included in most frequent category for analysis. ** Post-hoc analysis; result closest to but within the year prior to commencing treatment.

When controlling for other factors, current injecting drug or alcohol use, psychiatric illness, and cannabis or tobacco smoking were not significantly associated with lower treatment response rates. These are encouraging findings and add to existing evidence that such patients may be successfully treated. ${ }^{18}$ However, our previous study showed that patients with drug and alcoholrelated problems were less likely to be treated. ${ }^{10}$ Therefore, patients cur- rently receiving treatment represent a select group. The high treatment uptake reported in our previous study $(42 \%),{ }^{10}$ and the favourable treatment response in the current study, suggest that with appropriate patient and infrastructure support, expansion of treatment services to the broader HCV-infected community is warranted.

An important finding is that patients who achieved an SVR also had significantly improved markers of liver disease. In patients with an SVR, there was a 13-fold increase in the proportion with a normal ALT level and a twofold increase in normal APRI scores. Previous clinical trials and cohort studies have shown an association between SVR and normalisation of ALT levels as well as a correlation with improved histological activity. ${ }^{3,5,6,19}$ We were also able to show an improvement in APRI scores, consistent with regression of liver disease. ${ }^{20}$ 
There are a number of limitations with our study. First, the representativeness of our cohort in terms of all patients receiving treatment in Australia is unknown, as there is no register of clinics providing $\mathrm{HCV}$ treatment. However, the relatively large number and diversity of clinics included should enhance representativeness. Second, we did not measure any on-treatment factors including changes in drug and alcohol use, drug doses or treatment compliance. Third, the sample size for some categories, such as current injecting drug use and $>20 \mathrm{~g} /$ day of alcohol, may have been too small to detect any differences. However, there was no trend towards lower SVR rates in these groups. Fourth, we were unable to measure some potential pretreatment predictors of response (eg, detailed biochemical profiles, and host genetic markers of treatment response, in particular, IL28B genotype ${ }^{21}$ ) as this was an observational study. Tests for IL28B genotype are now available in Australia, and their widespread use is expected. Therefore, future observational studies should be able to examine this factor.

In addition to host genetic testing, new direct-acting antiviral (DAA) agents are becoming available. Two DAA agents - the protease inhibitors boceprevir and telaprevir - have been licensed in the United States and Europe, ${ }^{22}$ and in Australia. In Phase 3 clinical trials, the addition of these therapies increased treatment efficacy for treatment-naive genotype 1 patients by up to $30 \% .^{23,24}$ Further DAA agents are in clinical development, including polymerase and NS5A inhibitors that have crossgenotype activity. ${ }^{25}$ Our current study provides valuable baseline data for comparison with the real-world effectiveness of these agents once they are widely available in Australian clinics.

In conclusion, treatment response rates in the real-world Australian clinic setting are in concordance with those seen in clinical trials, despite the inclusion of patients with a broad range of comorbid conditions. Our findings provide valuable baseline data to measure the impact of imminent changes in patient management and suggest that expansion of treatment services to the broader HCVinfected community is warranted.

Acknowledgements: See acknowledgements online at mja.com.au.

Competing interests: Martin Weltman and Gregory Dore are members of the Roche and Merck Sharp and Dohme advisory boards. Joe Sasadeusz and Gregory Dore have received payment for travel scholarships, speakers bureaus and research grants from these companies.

Received 3 Jan 2012, accepted 29 Apr 2012.

1 Fried MW, Shiffman ML, Reddy KR, et al. Peginterferon alfa-2a plus ribavirin for chronic hepatitis C virus infection. N Engl J Med 2002; 347: 975-982

2 Hadziyannis SJ, Sette H Jr, Morgan TR, et al; PEGASYS International Study Group. Peginterferon-alpha2a and ribavirin combination therapy in chronic hepatitis $\mathrm{C}$ : a randomized study of treatment duration and ribavirin dose. Ann Intern Med 2004; 140: 346-355.

3 Manns MP, McHutchison JG, Gordon SC, et al. Peginterferon alfa-2b plus ribavirin compared with interferon alfa-2b plus ribavirin for initial treatment of chronic hepatitis C: a randomised trial. Lancet 2001; 358: 958-965.

4 McHutchison JG, Lawitz EJ, Shiffman ML, et al; IDEAL Study Team. Peginterferon alfa-2b or alfa$2 \mathrm{a}$ with ribavirin for treatment of hepatitis $C$ infection. N Engl J Med 2009; 361: 580-593.

5 Kumar D, Wallington-Beddoe C, George J, et al. Effectiveness of interferon alfa-2b/ribavirin combination therapy for chronic hepatitis $C$ in a clinic setting. Med J Aust 2003; 178: 267-271.

6 Gheorghe L, lacob S, Sporea I, et al. Efficacy, tolerability and predictive factors for early and sustained virologic response in patients treated with weight-based dosing regimen of PegIFN alpha-2b ribavirin in real-life healthcare setting. J Gastrointestin Liver Dis 2007; 16: 23-29.

7 Fattovich G, Covolo L, Pasino M, et al; Italian Hepatitis C Cohort Study Collaborative Group. The homeostasis model assessment of the insulin resistance score is not predictive of a sustained virological response in chronichepatitis C patients. Liver Int 2011; 31: 66-74.

8 Mauss S, Hueppe D, John C, et al. Estimating the likelihood of sustained virological response in chronic hepatitis C therapy. J Viral Hepat 2011; 18: e81-e90.

9 Hansen N, Obel N, Christensen PB, et al; Danish Database for Hepatitis B and C (DANHEP) group. Effectiveness of treatment with pegylated interferon and ribavirin in an unselected population of patients with chronic hepatitis $C$ : a Danish nationwide cohort study. BMC Infect Dis 2011; 11: 177.

10 Gidding HF, Law MG, Amin J, et al; ACHOS investigator team. Predictors of deferral of treatment for hepatitis C infection in Australian clinics. Med J Aust 2011; 194: 398-402.

11 Department of Health and Ageing. National hepatitis C resource manual. 2nd ed. Canberra: Commonwealth of Australia, 2008. http://www. health.gov.au/internet/main/publishing.nsf/ content/phd-hepc-manual-2008 (accessed May 2012).

12 Prati D, Taioli E, Zanella A, et al. Updated definitions of healthy ranges for serum alanine aminotransferase levels. Ann Intern Med 2002; 137: 1-10.

13 Wai CT, Greenson JK, Fontana RJ, et al. A simple noninvasive index can predict both significant fibrosis and cirrhosis in patients with chronic hepatitis C. Hepatology 2003; 38: 518-526.

14 Chung RT, Andersen J, Volberding P, et al; AIDS Clinical Trials Group A5071 Study Team. Peginterferon alfa-2a plus ribavirin versus interferon alfa-2a plus ribavirin for chronic hepatitis C in HIV-coinfected persons. NEngl J Med 2004; 351: 451-459.

15 Torriani FJ, Rodriguez-Torres M, Rockstroh JK, et al; APRICOT Study Group. Peginterferon alfa-2a plus ribavirin for chronic hepatitis C virus infection in HIV-infected patients. N Engl J Med 2004; 351 : 438-450.

16 Harrison SA, Rossaro L, Hu KQ, et al. Serum cholesterol and statin use predict virological response to peginterferon and ribavirin therapy. Hepatology 2010; 52: 864-874.

17 Honda A, Matsuzaki Y. Cholesterol and chronic hepatitis C virus infection. Hepatol Res 2011; 41: 697-710.

18 Hellard M, Sacks-Davis R, Gold J. Hepatitis C treatment for injection drug users: a review of the available evidence. Clin Infect Dis 2009; 49: 561-573.

19 Pockros PJ, Hamzeh FM, Martin P, et al. Histologic outcomes in hepatitis C-infected patients with varying degrees of virologic response to interferon-based treatments. Hepatology 2010; 52: 1193-1200.

20 Lin ZH, Xin YN, Dong QJ, et al. Performance of the aspartate aminotransferase-to-platelet ratio index for the staging of hepatitis C-related fibrosis: an updated meta-analysis. Hepatology 2011; 53: 726-736.

21 Thompson AJ, Muir AJ, Sulkowski MS, et al. Interleukin-28B polymorphism improves viral kinetics and is the strongest pretreatment predictor of sustained virologic response in genotype 1 hepatitis C virus. Gastroenterology 2010; 139: 120-129.

22 Schlütter J. Therapeutics: new drugs hit the target. Nature 2011; 474: S5-S7.

23 Jacobson IM, McHutchison JG, Dusheiko G, et al; ADVANCE Study Team. Telaprevir for previously untreated chronic hepatitis C virus infection. NEngl J Med 2011; 364: 2405-2416.

24 PoordadF, McCone J Jr, Bacon BR, et al; SPRINT-2 Investigators. Boceprevir for untreated chronic HCV genotype 1 infection. N Engl J Med 2011; 364: 1195-1206.

25 Gane E. Future hepatitis C virus treatment: interferon-sparing combinations. Liver Int 2011; 31 Suppl 1: 62-67. 